BMJ Open Sport \& Exercise Medicine

\title{
Hospital-treated injuries from horse riding in Victoria, Australia: time to refocus on injury prevention?
}

\author{
Siobhán O'Connor, ${ }^{1}$ Peta L Hitchens, ${ }^{2}$ Lauren V Fortington ${ }^{3}$
}

To cite: 0'Connor S, Hitchens PL, Fortington LV. Hospital-treated injuries from horse riding in Victoria, Australia: time to refocus on injury prevention? BMJ Open Sport \& Exercise Medicine 2018;4:e000321. doi:10.1136/ bmjsem-2017-000321

- Additional material is published online only. To view please visit the journal online (http://dx.doi.org/10.1136/ bmjsem-2017-000321).

Accepted 22 December 2017

Check for updates

${ }^{1}$ School of Health and Human Performance, Dublin City University, Dublin, Ireland ${ }^{2}$ Equine Centre, Melbourne Veterinary School, Faculty of Veterinary and Agricultural Sciences, University of Melbourne, Melbourne, Victoria, Australia

${ }^{3}$ Australian Centre for Research into Injury in Sport and its Prevention, Federation University Australia, Ballarat, Victoria, Australia

Correspondence to Dr Lauren V Fortington; I. fortington@federation.edu.au

\section{ABSTRACT}

Background The most recent report on hospitaltreated horse-riding injuries in Victoria was published 20 years ago. Since then, injury countermeasures and new technology have aimed to make horse riding safer for participants. This study provides an update of horse-riding injuries that required hospital treatment in Victoria and examines changes in injury patterns compared with the earlier study.

Methods Horse-riding injuries that required hospital treatment (hospital admission (HA) or emergency department (ED) presentations) were extracted from routinely collected data from public and private hospitals in Victoria from 2002-2003 to 2015-2016. Injury incidence rates per 100000 Victorian population per financial year and age-stratified and sex-stratified injury incidence rates are presented. Poisson regression was used to examine trends in injury rates over the study period.

Results ED presentation and HA rates were 31.1 and 6.6 per 100000 person-years, increasing by $28.8 \%$ and $47.6 \%$ from 2002 to 2016, respectively. Female riders (47.3 ED and 10.1 HA per 100000 person-years) and those aged between 10 and 14 years (87.8 ED and 15.7 HA per 100000 person-years) had the highest incidence rates. Fractures (ED 29.4\%; HA 56.5\%) and head injuries (ED 15.4\%; HA 18.9\%) were the most common injuries. HA had a mean stay of $2.6 \pm 4.1$ days, and the mean cost per HA was $\$ A 5096 \pm 8345$.

Conclusion Horse-riding injuries have remained similar in their pattern (eg, types of injuries) since last reported in Victoria. HA and ED incidence rates have increased over the last 14 years. Refocusing on injury prevention countermeasures is recommended along with a clear plan for implementation and evaluation of their effectiveness in reducing injury.

\section{INTRODUCTION}

Horse riding in Australia is a popular activity incorporating both organised, competitive sporting events and recreational activities. ${ }^{12}$ There are many different organised horse-riding sports, including professional and amateur horse racing, equestrian, eventing, show jumping, pony club, polo, hunting and rodeo. ${ }^{13}$ Horse riding is also enjoyed as a recreational activity, with participants riding along open roads or public trails, in a non-organised, informal setting, as an example.

\section{What are the new findings? \\ - There are more than 1600 emergency department presentations and 350 hospital admissions relating to horse-riding injuries per year in Victoria, an area with a population of 6179249 in 2015-2016. \\ - Female riders aged between 10 and 20 years had the highest rates of hospital-treated horse-riding injuries. \\ - Head injuries and fractures are the most common injuries treated in hospital. The pattern of injuries has remained similar compared with those reported previously.}

Injuries are an inherent risk in horse riding, with equipment and safety measures an important consideration for participation. Injuries and injury risks in horse-riding activities are different from other sports due to the human-animal interaction. ${ }^{1}{ }^{4}$ In a study from the early 1990s, 39\% of all horse riding-related injuries presenting to emergency departments (EDs) in the Australian state of Victoria were reportedly due to horse behaviour, with the majority of these occurring because the horse was frightened and bolted, bucked or reared. ${ }^{5}$

Horse-riding injury studies frequently report that fractures and head injuries comprise a large proportion of injuries. ${ }^{5-7}$ Not wearing a helmet, or wearing a substandard or incorrectly fitting helmet, is potentially associated with head injuries in horse riding. ${ }^{6-9} \mathrm{Up}$ to four in five injuries occur during horse riding itself, primarily due to riders falling. ${ }^{5}$ Many of these fall-related injuries require hospitalisation, ${ }^{15}$ owing to the rider being initially seated approximately $3 \mathrm{~m}$ above the ground ${ }^{4}$ and often riding over an irregular terrain. In other words, riders can fall from a height onto uneven ground. Injuries can also occur during horse handling and other non-riding activities centred around horses, such as grooming, saddling, shoeing, loading/ unloading and stable work. ${ }^{13}$ 
Recent studies from Queensland and New South Wales (NSW) suggest that the number of injuries in those states has remained constant in recent years; however, injury rates were not published. ${ }^{3} 10$ The last report on horseriding injuries in Victoria was published in the 1990s (as mentioned above), in which the injuries reported were primarily from falls, and crushing or kicking injuries from the horse itself. ${ }^{5}$ Head injuries comprised a large proportion of admissions, and admissions among women in private hospitals were twice as common compared with men. ${ }^{5}$

Following this, countermeasures for prevention of horse-riding injuries were developed that covered a range of areas including rules and regulations, rider education, equipment and clothing, rider experience, and the riding environment. ${ }^{1}$ More recently, advances have been made in the development of injury prevention strategies related to horse riding, including fall prevention programmes and equipment design (such as body protectors and helmets). ${ }^{411}{ }^{12}$ Evaluating whether such countermeasures have been implemented or have led to a reduction in injury over the years is a critical step in the injury prevention sequence. ${ }^{13}$ An epidemiological update of injuries in Victoria is required to determine if any changes have occurred in the types of injuries sustained and who they are sustained by. In addition, this information will facilitate identification of emerging areas for prevention with respect to current technology and safety standards.

The aim of this study was to investigate horse-related sport and recreation injuries that required either ED treatment or hospitalisation from 2002-2003 to 20152016 financial years inclusive, in Victoria, Australia. Specifically, data are presented to identify the number of horse-related sport and recreation injury cases and injuries per participant-years, as well as to enable examination of injuries with regard to age, sex, body region, type, mechanism, activity, location and outcome of injury. A secondary aim was to compare the new injury data with those collected in the 1990s. ${ }^{5}$

\section{METHODS}

Ethics

Individual consent was not required as the data were obtained as part of the admissions process in a hospital setting for routine Australian Government statistics.

\section{Injury data}

De-identified, summarised data on all horse-related injuries relating to sport and recreation were sought from the Victorian Injury Surveillance Unit and extracted from two data sets- the Victorian Emergency Minimum Dataset (VEMD) and the Victorian Admitted Episodes Dataset (VAED). The VEMD records all cases where a person sought treatment for an injury at one of the 39 Victorian EDs in public hospitals in Victoria, inclusive of all public hospitals with a 24-hour service. The data are coded according to the National Injury Surveillance Data
Dictionary. ${ }^{14}$ The VAED records data related to all statewide hospital admissions (HA), including private and public hospitals, rehabilitation centres, extended care facilities and day procedure centres across Victoria.

For HA, a request was made for cases with International Statistical Classification of Diseases and Related Health Problems, 10th Revision, Australian Modification $^{15}$ activity classification code U63.0 (equestrian activities; online supplementary table 1 ). This code includes all equestrian sport and recreation, exclusive of modern pentathlon (U67.3). Admissions as a result of a transfer from another hospital, readmissions for day treatments within 30 days of the initial admission, prearranged admissions or return visits were excluded to prevent inclusion of the same injury multiple times. Cases were included from 1 July 2002 to 30 June 2016 per financial year. For ED presentations, a text narrative search of key horse-riding sport terms was used to identify cases.

Patient age, gender, principal injury diagnosis (including body region and type of injury), mechanism of injury, activity and location at time of injury, financial year, outcome of injury, and region of primary residence in Victoria were all extracted. For ED presentations only, the mechanism of injury was examined. For HA, the length of stay in hospital and economic burden due to this stay were extracted.

\section{Population and participation data}

The estimated Victorian population, as a total and by age and sex, was obtained from the Australian Bureau of Statistics. ${ }^{16}$ This is the most accurate data available on which to calculate HA and ED presentation incidence rates (ie, using the population as denominator). For non-organised, general horse-riding participation, an estimate of the proportion of people who took part in equestrian and horse-riding activities was obtained from the Exercise, Recreation and Sport Survey annual report state tables for Victoria, covering the years 2007-2008 to 2010-2011, inclusive. ${ }^{17}$ The proportion of non-organised participants (as a \% of state population) was used as a comparator to the HA and ED cases for trail or general horse-riding injuries (excluding cases from other horse sports). This was because general trail riding was the only activity in which the injury cases could be separately derived.

\section{Statistical analysis}

Descriptive data (mean, SD $( \pm)$ and range) for the length of stay in hospital as well as the estimated cost of hospital stay $(\$ \mathrm{~A})$ are reported. Proportions of injuries by age, sex, body region injured, type of injury, mechanism of injury, activity at time of injury and geographical location at time of injury, as well as discharge destination for ED, are also presented.

Crude injury incidence rates for both ED presentations and HA were calculated per 100000 person-years for the Victorian population for each financial year, with $95 \%$ CI, using the Poisson distribution. Percentage change 
comparing the injury rate in 2002-2003 and 2015-2016 was calculated. Age-stratified and sex-stratified injury incidence rates and their 95\% CI are presented. To identify trends in injury incidence rates over the 14 years of the study, we generated incidence rate ratios (IRR) and their 95\% CIs using Poisson regression with a linear term for financial year. Differences were considered to be statistically significant where $\mathrm{P}<0.05$. Injury incidence rates specific to non-organised trail or general horse riding were calculated separately using participation estimates for the years 2007-2008 to 2010-2011. IRR and $95 \% \mathrm{CI}$ were also calculated between the three age groups most commonly injured, sex, and the differences between 2007-2008 and 2010-2011 for trail and general horse-riding injuries. Data were analysed using Stata V.13.1 and Microsoft Excel 2016.

\section{RESULTS}

There were 23702 ED presentations and an additional 5031 HA due to horse-related injuries between July 2002 and June 2016. For ED presentations and HA, an incidence rate of 31.1 and 6.6 per 100000 person-years was reported over the study period, respectively. There was an increase of $28.8 \%$ ED presentations and $47.6 \%$ HA over the 14 years. Female riders sustained a greater proportion of horse-riding injuries than male riders for both ED presentation (76.8\%) and HA (76.9\%). Table 1 presents injury incidence rates stratified by year,

Table 1 Number, percentage, population, injury incidence rates per 100000 person-years and $95 \% \mathrm{Cl}$ for ED presentations and HA per year, sex, most common age groups injured, and trail or general horse-riding injuries

\begin{tabular}{|c|c|c|c|c|c|c|}
\hline \multirow[b]{2}{*}{ Study factor } & \multicolumn{3}{|l|}{ ED } & \multicolumn{3}{|l|}{ HA } \\
\hline & n (\%) & $\begin{array}{l}\text { Population at } \\
\text { risk }\end{array}$ & IR (95\% Cl) & n (\%) & $\begin{array}{l}\text { Population at } \\
\text { risk }\end{array}$ & IR (95\% CI) \\
\hline \multicolumn{7}{|l|}{ Year } \\
\hline 2002-2003 & $1251(6.2)$ & 4873809 & 25.7 (25.7 to 25.7 ) & $312(5.3)$ & 4873809 & 6.4 (6.4 to 6.4$)$ \\
\hline 2003-2004 & $1379(6.5)$ & 4927149 & 28.0 (28.0 to 28.0 ) & $325(5.8)$ & 4927149 & 6.6 (6.6 to 6.6$)$ \\
\hline 2004-2005 & $1571(6.4)$ & 4989246 & 31.5 (31.5 to 31.5$)$ & $322(6.6)$ & 4989246 & 6.5 (6.5 to 6.5$)$ \\
\hline 2005-2006 & $1757(6.1)$ & 5061266 & 34.7 (34.7 to 34.7 ) & $306(7.4)$ & 5061266 & 6.1 (6.0 to 6.1$)$ \\
\hline 2006-2007 & $1691(5.9)$ & 5153522 & 32.8 (32.8 to 32.8 ) & $296(7.1)$ & 5153522 & 5.7 (5.7 to 5.8$)$ \\
\hline $2007-2008$ & $1488(5.5)$ & 5256375 & 28.3 (28.3 to 28.3 ) & $274(6.3)$ & 5256375 & 5.2 (5.2 to 5.2$)$ \\
\hline 2008-2009 & $1706(5.9)$ & 5371934 & 31.8 (31.7 to 31.8$)$ & $296(7.2)$ & 5371934 & 5.5 (5.5 to 5.5$)$ \\
\hline 2009-2010 & $1673(6.0)$ & 5461101 & 30.6 (30.6 to 30.7$)$ & $304(7.1)$ & 5461101 & 5.6 (5.6 to 5.6$)$ \\
\hline 2010-2011 & 1607 (6.3) & 5537817 & 29.0 (29.0 to 29.0 ) & $318(6.8)$ & 5537817 & 5.7 (5.7 to 5.8$)$ \\
\hline 2011-2012 & $1730(6.6)$ & 5653429 & 30.6 (30.6 to 30.6$)$ & $332(7.3)$ & 5653429 & 5.9 (5.9 to 5.9$)$ \\
\hline 2012-2013 & $1902(7.6)$ & 5775808 & 32.9 (32.9 to 33.0) & $382(8.0)$ & 5775808 & 6.6 (6.6 to 6.6$)$ \\
\hline 2013-2014 & $1825(8.2)$ & 5901970 & 30.9 (30.9 to 31.0$)$ & $410(7.7)$ & 5901970 & 7.0 (6.9 to 7.0$)$ \\
\hline 2014-2015 & 2079 (11.3) & 6032968 & 34.5 (34.4 to 34.5 ) & $570(8.8)$ & 6032968 & 9.5 (9.4 to 9.5$)$ \\
\hline 2015-2016 & $2043(11.6)$ & 6179249 & 33.1 (33.0 to 33.1 ) & $584(8.6)$ & 6179249 & 9.5 (9.4 to 9.5$)$ \\
\hline \multicolumn{7}{|l|}{ Sex } \\
\hline Male & 5501 (23.1) & 37682369 & $14.6(14.2$ to 15.0$)$ & $1161(76.8)$ & 37682369 & 3.1 (2.9 to 3.3 ) \\
\hline Female & $18201(76.9)$ & 38493274 & 47.3 (46.6 to 48.0$)$ & $3870(23.2)$ & 38493274 & 10.1 (9.7 to 10.4$)$ \\
\hline \multicolumn{7}{|l|}{ Age group } \\
\hline $10-14$ & 4109 (17.3) & 4681122 & 87.8 (85.1 to 90.5$)$ & 735 (14.6) & 4681122 & 15.7 (14.6 to 16.9$)$ \\
\hline $15-19$ & $3113(13.1)$ & 4950196 & 62.9 (60.7 to 65.1$)$ & $655(13.0)$ & 4950196 & 14.3 (12.3 to 14.3 ) \\
\hline $20-24$ & $2390(10.1)$ & 5545199 & 43.1 (41.4 to 44.9$)$ & $489(13.0)$ & 5545199 & 8.8 (8.1 to 9.6$)$ \\
\hline \multicolumn{7}{|l|}{ Trail or general } \\
\hline 2007-2008 & 70 (19.9) & 26282 & 266.3 (210.7 to 336.7$)$ & $207(22.1)$ & 26282 & 787.6 (687.3 to 902.6$)$ \\
\hline 2008-2009 & $112(31.8)$ & 42975 & 260.6 (216.6 to 313.6$)$ & $229(24.4)$ & 42975 & 532.9 (468.1 to 606.6$)$ \\
\hline 2009-2010 & 96 (27.3) & 43689 & 219.7 (179.9 to 268.4 ) & $245(26.1)$ & 43689 & 560.8 (494.8 to 635.6$)$ \\
\hline 2010-2011 & $74(21.0)$ & 38765 & 190.9 (152.0 to 239.7$)$ & $256(27.3)$ & 38765 & $660.4(584.3$ to 746.5$)$ \\
\hline $\begin{array}{l}\text { Total population } \\
\text { at risk }\end{array}$ & 23702 & & 31.1 (31.1 to 31.1$)$ & 5031 & & 6.6 (6.6 to 6.6$)$ \\
\hline
\end{tabular}

ED, emergency department; HA, hospital admission; IR, incidence rate. 
sex and age groups most commonly injured. We found an increase in HA for female riders from 2013-2014 to 2014-2015 (IRR 1.40; 95\% CI 1.22 to 1.61 ).

Trail or general horse-riding injuries presented with an average HA of 617.6 (95\% CI 579.3 to 658.5 ) and ED presentations of 232.0 (95\% CI 209.0 to 257.6) per 100000 non-organised horse-riding participants per year. ED presentations (IRR 0.87; 95\% CI 0.67 to 1.1 ) and HA (IRR $0.84 ; 95 \%$ CI 0.70 to 1.01 ) decreased between 2007 2008 and 2010-2011; however, this was not statistically significant.

People aged 10-14 years, followed by 15-19 years and 20-24 years, were the most commonly injured in both the ED presentations and HA. Those aged 10-14 years had a greater incidence of presentations to the ED (IRR 1.19; 95\% CI 1.07 to 1.32 ) and HA (IRR $1.40 ; 95 \%$ CI 1.34 to 1.47) than those aged 15-19years old. Those aged 15-19 years had a greater injury incidence than those aged 20-24years old for both ED presentations (IRR 1.51; 95\% CI 1.34 to 1.70 ) and HA (IRR $1.46 ; 95 \%$ CI 1.38 to $1.54)$.

Table 2 presents the body region of injuries. The head was the most common body region injured for both ED presentations and HA. In ED presentations, injuries to the wrist and hand and foot and ankle were also common. Injuries to the abdomen, lower back, lumbar spine, pelvis, and elbow and forearm accounted for a relatively large proportion of HA. Fractures were most common for both ED presentations and admissions to hospital. In the ED, dislocations, sprains and strains were the second most common type of injury reported.

Where the specific site was reported, horse-related injuries that presented to the ED occurred most often on a farm $(25.1 \%)$ or at home $(22.2 \%)$. Similarly, of those that could be specified, horse-related injuries that required hospital admittance mainly occurred in sports and athletic areas (17.4\%).

Most cases that presented to an ED occurred during leisure $(65.7 \%)$ and sports $(10.0 \%)$. For ED presentations, most injuries were due to a fall from a horse, or being struck or bitten by a horse $(56.0 \%)$ (Table 3 ). Transport was the primary cause of horse-related injuries that required HA $(88.0 \%)$.

The mean length of stay in a hospital was 2.6 \pm 4.1 (1-101) days, with the majority in hospital for less than 2 days $(57.1 \%)$, followed by $2-7$ days $(37.0 \%), 8-30$ days $(5.4 \%)$ and greater than 31 days $(0.4 \%)$. The mean cost of horse-related injuries following HA was $\mathrm{A} \$ 5096 \pm 8345$ (A \$631-A \$188412).

\section{DISCUSSION}

This study presents an update of ED presentations and HA as a result of horse-riding injuries in Victoria, Australia. The number of hospital-treated horse-riding injuries has increased over the last 14 years. While this can initially appear to be of concern, further analysis with accurate participation data to enable stronger comparison of incidence rates is required, as the change may be
Table 2 Body region injured, type of injury and location of injury occurrence for ED presentations and HA from 20022003 to $2015-2016$

\begin{tabular}{|c|c|c|c|c|}
\hline & \multicolumn{2}{|c|}{ ED presentations } & \multicolumn{2}{|l|}{ HA } \\
\hline & $\mathbf{n}$ & Percentage & $\mathbf{n}$ & Percentage \\
\hline \multicolumn{5}{|l|}{ Body region injured } \\
\hline Head & 3641 & 15.4 & 951 & 18.9 \\
\hline Neck & 904 & 3.8 & 215 & 4.3 \\
\hline $\begin{array}{l}\text { Shoulder and } \\
\text { upper arm }\end{array}$ & 2242 & 9.5 & 637 & 12.7 \\
\hline $\begin{array}{l}\text { Elbow and } \\
\text { forearm }\end{array}$ & 2040 & 8.6 & 682 & 13.6 \\
\hline Wrist and hand & 3314 & 14.0 & 245 & 4.9 \\
\hline Thorax & 1255 & 5.3 & 471 & 9.4 \\
\hline $\begin{array}{l}\text { Abdomen, spine } \\
\text { and pelvis }\end{array}$ & 2271 & 9.6 & 850 & 16.9 \\
\hline Hip and thigh & 1090 & 4.6 & 281 & 5.6 \\
\hline $\begin{array}{l}\text { Knee and lower } \\
\text { leg }\end{array}$ & 1865 & 7.9 & 578 & 11.5 \\
\hline Ankle and foot & 2659 & 11.2 & 92 & 1.8 \\
\hline Eye & 34 & 0.1 & 0 & 0.0 \\
\hline $\begin{array}{l}\text { Ear, respiratory } \\
\text { tract and } \\
\text { alimentary tract }\end{array}$ & 10 & 0.0 & 0 & 0.0 \\
\hline $\begin{array}{l}\text { Unspecified body } \\
\text { region }\end{array}$ & 343 & 1.4 & 15 & 0.3 \\
\hline $\begin{array}{l}\text { Body region not } \\
\text { required }\end{array}$ & 27 & 0.1 & 14 & 0.3 \\
\hline
\end{tabular}

Type of injury

\begin{tabular}{|c|c|c|c|c|}
\hline Fracture & 6963 & 29.4 & 2843 & 56.5 \\
\hline $\begin{array}{l}\text { Dislocation, } \\
\text { sprain, strain }\end{array}$ & 5372 & 22.7 & 226 & 4.5 \\
\hline $\begin{array}{l}\text { Other and } \\
\text { unspecified injury }\end{array}$ & 3492 & 14.7 & 680 & 13.5 \\
\hline Superficial injury & 2685 & 11.3 & 258 & 5.1 \\
\hline $\begin{array}{l}\text { Muscle and } \\
\text { tendon }\end{array}$ & 1586 & 6.7 & 73 & 1.5 \\
\hline Open wound & 1401 & 5.9 & 159 & 3.2 \\
\hline Intracranial injury & 1108 & 4.7 & 536 & 10.7 \\
\hline Crushing injury & 511 & 2.2 & $11^{*}$ & 0.2 \\
\hline Eye injury & 77 & 0.3 & - & - \\
\hline $\begin{array}{l}\text { Poisoning or } \\
\text { toxic effects }\end{array}$ & 45 & 0.2 & - & - \\
\hline Burns & 27 & 0.1 & - & - \\
\hline $\begin{array}{l}\text { Injury to internal } \\
\text { organs }\end{array}$ & 249 & 1.1 & 182 & 3.6 \\
\hline Foreign body & 66 & 0.3 & 0 & 0.0 \\
\hline $\begin{array}{l}\text { Traumatic } \\
\text { amputation }\end{array}$ & 49 & 0.2 & 15 & 0.3 \\
\hline $\begin{array}{l}\text { Injury to blood } \\
\text { vessels }\end{array}$ & 32 & 0.1 & 9 & 0.2 \\
\hline
\end{tabular}

Continued 


\begin{tabular}{|c|c|c|c|c|}
\hline & \multicolumn{2}{|c|}{ ED presentations } & \multicolumn{2}{|l|}{ HA } \\
\hline & $\mathrm{n}$ & Percentage & $\mathbf{n}$ & Percentage \\
\hline $\begin{array}{l}\text { Injury to nerves } \\
\text { and spinal cord }\end{array}$ & 32 & 0.1 & 28 & 0.6 \\
\hline $\begin{array}{l}\text { Other and } \\
\text { unspecified } \\
\text { effects of external } \\
\text { causes }\end{array}$ & 7 & 0.0 & 11 & 0.2 \\
\hline \multicolumn{5}{|l|}{$\begin{array}{l}\text { Location of injury } \\
\text { occurrence }\end{array}$} \\
\hline Farm & 5940 & 25.1 & 241 & 4.8 \\
\hline Home & 5273 & 22.2 & 222 & 4.4 \\
\hline $\begin{array}{l}\text { Sports and } \\
\text { athletic areas }\end{array}$ & 1999 & 8.4 & 874 & 17.4 \\
\hline $\begin{array}{l}\text { Road, street and } \\
\text { highway }\end{array}$ & 562 & 2.4 & 77 & 1.5 \\
\hline $\begin{array}{l}\text { Trade and service } \\
\text { area }\end{array}$ & 222 & 0.9 & $16 \dagger$ & 0.3 \\
\hline $\begin{array}{l}\text { School and } \\
\text { public buildings }\end{array}$ & 100 & 0.4 & - & - \\
\hline $\begin{array}{l}\text { Residential } \\
\text { institution }\end{array}$ & 29 & 0.1 & - & - \\
\hline $\begin{array}{l}\text { Industrial and } \\
\text { construction area }\end{array}$ & 24 & 0.1 & - & - \\
\hline $\begin{array}{l}\text { Other specified } \\
\text { places }\end{array}$ & 7013 & 29.6 & 349 & 6.9 \\
\hline $\begin{array}{l}\text { Unspecified } \\
\text { places }\end{array}$ & 2540 & 10.7 & 3252 & 64.6 \\
\hline
\end{tabular}

${ }^{*}$ Crushing injury, eye injury, poisoning or toxic effects, and burns are presented as grouped data due to small numbers.

†Trade and service area, school and public buildings, residential institution, and industrial and construction area are presented as grouped data due to small numbers.

ED, emergency department; HA, hospital admissions.

accounted for by an increased number of participants. Only a limited selection of participation data were available for 3 years of trail or horse-riding injuries. In this, a trend for a reduction in injuries between 2007-2008 and 2010-2011 was observed, but the decrease was not statistically significant.

\section{Who is at risk?}

In Victoria, the ratio of women to men requiring hospital-treated injuries has increased from 2:1 reported by previous research in the $1990 \mathrm{~s}^{5}$ to $3: 1$ over the last 14 years. The findings in Victoria are similar to the 2.8:1 ratio noted in a hospital in $\mathrm{NSW},{ }^{10}$ but higher than in Queensland at 1.2:1. ${ }^{3}$ Young female riders aged between 10 and 20 years are still at greatest risk of sustaining horse-riding injuries requiring hospital treatment in Victoria, most likely reflecting the high participation rates of this population than other age and sex groups. ${ }^{18}$ However, the percentage of ED presentations aged 10-14 years has reduced by $6.7 \% .^{5}$ Hospital-based research in
Queensland, ${ }^{3}$ United Arab Emirates, ${ }^{19}$ New Zealand ${ }^{18}$ and the USA ${ }^{20}$ supports this finding, highlighting women and older children/adolescents aged between 10 and 19 years as those at most risk of horse-riding injury.

While a trend for decreased HA from injuries that occurred during trail or general horse-riding injuries was noted, it was not statistically significant. Recent research in New Zealand ${ }^{21}$ has highlighted the injury risk during non-organised recreational horse-riding activities. This highlights the need for research to recommend and implement injury prevention strategies in organised horse-riding sports, and to tackle how best to implement these strategies in non-organised horse-riding activities.

\section{How does it happen?}

Falling from or being struck or bitten by a horse and falling from a height were frequent mechanisms of injury. Falls were also the most prevalent injury mechanism reported back in 1995, with as much as $77 \%$ of injuries occurring due to a fall. ${ }^{5}$ This is supported by previous hospital data from Queensland, ${ }^{3}$ Perth Royal Hospital, ${ }^{19}$ New Zealand $^{21}$ and the USA. ${ }^{20}$ While fall techniques have long been promoted, mandatory fall prevention programmes that teach appropriate fall technique strategies at a young age may be valuable. In addition, new advancements have been made with safety equipment and their application in horse riding, ${ }^{34}$ so updated countermeasure recommendations may be required.

\section{What are the common injuries?}

Head injuries were the most frequent body region injured. This was slightly higher than previously reported ED presentations in both children (13\%) and adults $(12 \%)$ in Victoria ${ }^{5}$ and similar to the $15.5 \%$ of injuries recorded on the Queensland Trauma Registry. ${ }^{3}$ Helmets have the potential to drastically reduce the number of severe and fatal head injuries ${ }^{22} 23$ and are significantly associated with lower HA rates. ${ }^{10}$ In Australia, many equestrian sport organisations have rules in place to ensure helmet use is mandatory during riding. ${ }^{12}$ However, a US study found that the majority $(91.9 \%)$ of those sustaining

Table 3 Mechanism of horse-related injury for emergency department (ED) presentations between 2002-2003 and 2015-2016

\begin{tabular}{lrl}
\hline & \multicolumn{2}{c}{ ED presentations } \\
\cline { 2 - 3 } Mechanism & $\mathbf{n}$ & Percentage \\
\hline Fall from, struck or bitten by horse & 13278 & 56.0 \\
\hline Fall from >1 m & 4105 & 17.3 \\
\hline Fall from same level or <1 m & 2756 & 11.6 \\
\hline Bite/kick/stomp/crush & 1822 & 7.7 \\
Collision with object & 991 & 4.2 \\
Cutting, piercing injuries & 27 & 0.1 \\
Other specified causes & 501 & 2.1 \\
Unspecified causes & 222 & 0.9 \\
\hline
\end{tabular}


horse-related injuries did not wear any safety equipment. ${ }^{20}$ In Victoria, Australia between 2003 and 2008, the situation was only marginally better, as $31 \%$ of people aged less than 18 years were not wearing a helmet during the injury event, ${ }^{24}$ and $43 \%$ in a 1995 study. ${ }^{25}$ Exploration of risk perceptions and protective equipment behaviours could provide further insight as to why riders do not wear helmets. In addition, new advancements have been made for horse-riding safety equipment, ${ }^{11}{ }^{12}$ and so updated recommendations may be required.

Fractures have remained the most common type of injury in comparison with the previous analysis, but dislocations, sprains and strains have increased. ${ }^{5}$ Wrist, hand and elbow fractures were frequent, possibly because these types of injuries are commonly associated with falls from a horse, where the rider may fall with their arms outstretched. ${ }^{19}$ Abdomen, spine and pelvic injuries were the second most common body region requiring HA. The use of protective vests may reduce the risk of injury to the trunk; however, only $7 \%$ of US horse riders classified as novice to professionals wore them, ${ }^{26}$ and so an examination of the use of protective vests in horse riders in Victoria would be beneficial.

\section{Outcomes of the injuries}

In Victoria, the mean days of HA has decreased from 4 days ${ }^{5}$ to 2.6 days, possibly indicating that the countermeasures implemented may have led to a reduction in the overall injury severity and burden, or as a reflection of a change in the healthcare treatment. However, horse-related injuries led to a substantial financial burden. Unfortunately, costing data were not available from the previous analysis in Victoria completed in the 1990s, which limits comparison. When converted to enable comparison with other currencies, the financial impact of a horse-riding injury HA in Victoria was higher than the reported cost in New Zealand $(\mathrm{NZ} \$ 3000)^{21}$ but lower than the USA (US\$29 654). ${ }^{20}$ This may be due to varying hospital costs between countries and treatments. ${ }^{27}$ Horse-riding injuries are often serious and have a high financial burden, highlighting the clear need for their prevention to be prioritised.

\section{Limitations}

This study examined horse-related injuries that were presented to the ED or were admitted to hospital only. Thus, injuries that did not require hospitalisation and were presented solely to their local general practice or healthcare professional were not included. Injury rates were primarily expressed with respect to population data, as accurate participation in horse riding was not available for the full time period examined. Establishing accurate participation data of both organised and non-organised horse riding would provide more accurate rates.

\section{CONCLUSION}

Despite previous countermeasures having been proposed following the last report on horse-riding injuries in Victoria in the 1990s, injuries that require hospital treatment are still prevalent. Thus, detailed examination of the countermeasures previously proposed, their adaptation to policy, and their implementation and uptake across both organised and non-organised horse riding is recommended.

Acknowledgements The authors thank the team at the Victorian Injury Surveillance Unit, Monash University Australia, for providing the data used in this study.

Contributors SOC and LVF conceived the study. SOC completed the data analysis. SOC and LVF wrote the first draft of the manuscript, and all authors critically reviewed the work before approving the final version of the manuscript. All authors will act as study guarantors for this paper.

Funding This paper was funded by the Irish Research Council New Foundations scheme. ACRISP is one of the international research centres for the prevention of injury and protection of athlete health supported by the IOC. PLH is supported by funding from Racing Victoria (RVL), the Victorian Racing Industry Fund (VRIF) of the Victorian State Government, and the University of Melbourne.

\section{Competing interests None declared.}

Ethics approval Ethical approval was obtained from the Federation University Australia Human Research Ethics Committee (C17-020)

Provenance and peer review Not commissioned; externally peer reviewed.

Open Access This is an Open Access article distributed in accordance with the Creative Commons Attribution Non Commercial (CC BY-NC 4.0) license, which permits others to distribute, remix, adapt, build upon this work non-commercially, and license their derivative works on different terms, provided the original work is properly cited and the use is non-commercial. See: http://creativecommons.org/ licenses/by-nc/4.0/

(C) Article author(s) (or their employer(s) unless otherwise stated in the text of the article) 2018. All rights reserved. No commercial use is permitted unless otherwise expressly granted.

\section{REFERENCES}

1. Watt GM, Finch CF. Preventing equestrian injuries. Sports Medicine 1996;22:187-97.

2. Australian Sports Commission. Participation in horse activities by australian children 2003-2012. 2013.

3. Lang J, Sathivelu M, Tetsworth K, et al. The epidemiology of horse-related injuries for different horse exposures, activities, and age groups in Queensland, Australia. J Trauma Acute Care Surg 2014;76:205-12.

4. O'Connor S, Warrington G, McGoldrick A, et al. Epidemiology of injury due to race-day jockey falls in professional flat and jump horse racing in Ireland, 2011-2015. J Athl Train 2017;52:1140-6.

5. Williams F, Ashby K. Horse related injuries. Hospital 1992;1989.

6. Silver JR, Parry JM. Hazards of horse-riding as a popular sport. $\mathrm{Br} \mathrm{J}$ Sports Med 1991;25:105-10.

7. Nelson DE, Bixby-Hammett D. Equestrian injuries in children and young adults. Am J Dis Child 1992;146:611-4.

8. Bixby-Hammett DM. Pediatric equestrian injuries. Pediatrics 1992;89:832-6.

9. Hobbs GD, Yealy DM, Rivas J. Equestrian injuries: a five-year review. J Emerg Med 1994;12:143-5.

10. Lim J, Puttaswamy V, Gizzi M, et al. Pattern of equestrian injuries presenting to a Sydney teaching hospital. ANZ J Surg 2003;73:567-71.

11. Gibson T, Thai K, Saxon J, et al. The effectiveness of jockey safety equipment in falls. J Biomech 2007;40:S133.

12. Theodore JE, Theodore SG, Stockton KA, et al. Paediatric horserelated trauma. J Paediatr Child Health 2017;53.

13. Finch $C$. A new framework for research leading to sports injury prevention. J Sci Med Sport 2006:9:3-9.

14. Australian Institute of Health and Welfare. Injury surveillance national minimum data set. Canberra: Australian Institute of Health and Welfare, 2003.

15. National Centre for Classification in Health. The international statistical classification of diseases and related health problems Australian modification (ICD-10-AM). 3rd edn. Australia: National Centre for Classification in Health, 2002.

16. Australian Bureau of Statistics. 3101.0 Estimated resident population, states and territories 2017. 2017. 
17. Australian Sports Commission. Exercise, Recreation and Sport Survey (ERASS) annual report 2010. 2017.

18. Buckley SM, Chalmers DJ, Langley JD. Injuries due to falls from horses. Aust J Public Health 1993;17:269-71.

19. Abu-Zidan FM, Rao S. Factors affecting the severity of horse-related injuries. Injury 2003;34:897-900.

20. Davidson SB, Blostein PA, Schrotenboer A, et al. Ten years of equine-related injuries: severity and implications for emergency physicians. J Emerg Med 2015;49:605-12.

21. Smartt P, Chalmers D. A new look at horse-related sport and recreational injury in New Zealand. J Sci Med Sport 2009;12:376-82.

22. Chitnavis JP, Gibbons CL, Hirigoyen M, et al. Accidents with horses: what has changed in 20 years? Injury 1996;27:103-5.
23. Ingemarson $\mathrm{H}$, Grevsten $\mathrm{S}$, Thorén $\mathrm{L}$, et al. Lethal horse-riding injuries. J Trauma 1989;29:25-30.

24. Papachristos A, Edwards E, Dowrick A, et al. A description of the severity of equestrian-related injuries (ERIs) using clinical parameters and patient-reported outcomes. Injury 2014;45:1484-7.

25. Lower T, Wolfenden K. Preventing horse related injury - a pilot education program. Health Promot J Austr 1995;5:46-50.

26. Mayberry JC, Pearson TE, Wiger KJ, et al. Equestrian injury prevention efforts need more attention to novice riders. J Trauma 2007;62:735-9.

27. Anderson GF, Reinhardt UE, Hussey PS, et al. It's the prices, stupid: why the United States is so different from other countries. Health Aff 2003;22:89-105. 